University of Nebraska - Lincoln

DigitalCommons@University of Nebraska - Lincoln

U.S. Department of Veterans Affairs Staff

Publications

U.S. Department of Veterans Affairs

2008

IQ decline in cross-sectional studies of schizophrenia:

Methodology and interpretation

\author{
William S. Kremen \\ University of California - San Diego, wkremen@ucsd.edu \\ Larry J. Seidman \\ Beth Israel Deaconess Medical Center \\ Stephen V. Faraone \\ Veterans Affairs San Diego Healthcare System \\ Ming T. Tsuang \\ University of California - San Diego, mtsuang@ucsd.edu
}

Follow this and additional works at: https://digitalcommons.unl.edu/veterans

Kremen, William S.; Seidman, Larry J.; Faraone, Stephen V.; and Tsuang, Ming T., "IQ decline in crosssectional studies of schizophrenia: Methodology and interpretation" (2008). U.S. Department of Veterans Affairs Staff Publications. 44.

https://digitalcommons.unl.edu/veterans/44

This Article is brought to you for free and open access by the U.S. Department of Veterans Affairs at DigitalCommons@University of Nebraska - Lincoln. It has been accepted for inclusion in U.S. Department of Veterans Affairs Staff Publications by an authorized administrator of DigitalCommons@University of Nebraska - Lincoln. 


\title{
IQ decline in cross-sectional studies of schizophrenia: Methodology and interpretation
}

\author{
William S. Kremen ${ }^{a, *}$, Larry J. Seidman ${ }^{\text {b,c,d,e }}$, \\ Stephen V. Faraone f,g , Ming T. Tsuang ${ }^{\text {a,d }, e, f, g}$ \\ a Department of Psychiatry, Center for Behavioral Genomics, University of California, San Diego School of Medicine, \\ 9500 Gilman Drive (MC 0738), La Jolla, CA 92093-0738, USA \\ ${ }^{\mathrm{b}}$ Harvard Medical School Departments of Psychiatry at Massachusetts Mental Health Center Division of Public Psychiatry, \\ Beth Israel Deaconess Medical Center, Boston, MA 02215, USA \\ ${ }^{\mathrm{c}}$ Massachusetts General Hospital, Boston, MA 02214, USA \\ ${ }^{\mathrm{d}}$ Harvard Institute of Psychiatric Epidemiology and Genetics, Boston, MA 02115, USA \\ e Department of Psychiatry and Behavioral Sciences, State University of New York Upstate Medical University, \\ 750 East Adams Street, Syracuse, NY, USA \\ ${ }^{\mathrm{f}}$ Harvard Departments of Epidemiology and Psychiatry, 25 Shattuck Street, Boston, MA 02115, USA \\ ${ }^{g}$ Veterans Affairs San Diego Healthcare System, La Jolla, CA 92161, USA
}

Received 29 March 2005; received in revised form 19 December 2005; accepted 12 January 2006

\begin{abstract}
Some researchers have compared neuropsychological performance in schizophrenia groups with and without presumed IQ decline. Inherent in this approach is an assumption that group differences are due to different IQ trajectories (stable vs. declining), but neuropsychological differences could be a function of current IQ regardless of the presence or absence of previous IQ decline. We examined this issue in 93 normal controls and in 80 patients classified as having preserved (27.5\%), deteriorated (50\%), or compromised (22.5\%) intellect based on IQ and reading recognition-IQ difference scores. We also examined group differences in verbal and performance IQ. Deteriorated patients had the largest verbal performance-IQ differences. They were more neuropsychologically impaired than the preserved group (average effect size $=0.43$ ), but deteriorated patients also had significantly lower current IQs. When subgroups of preserved and deteriorated patients with equivalent current IQs were compared, neuropsychological differences were essentially eliminated (average effect size $=0.10$ ); however, both groups were significantly more impaired than controls with similar IQs. Neuropsychological impairment, even in patients with apparently preserved IQ, is consistent with a prefrontal-dysexecutive syndrome. Overall, these results strongly suggest that differences in current neuropsychological function in schizophrenia are attributable primarily to current IQ instead of to IQ trajectory over time.
\end{abstract}

(C) 2008 Published by Elsevier Ireland Ltd.

Keywords: IQ decline; Preserved IQ; Executive dysfunction

* Corresponding author. Tel.: +1 858822 2393; fax: +1 8588225856.

E-mail address: wkremen@ucsd.edu (W.S. Kremen).

\section{Introduction}

Elucidating the course of intellectual-cognitive function and discerning meaningful neurocognitive subgroups or subtypes are important components for 
understanding the nature of neurocognitive impairment in schizophrenia. By developing a strategy in which schizophrenia subgroups were defined on the basis of both current IQ and the presence/absence of putative IQ decline over time, Weickert et al. (2000) essentially integrated these two issues. Badcock et al. (2005) subsequently applied the same strategy to an independent sample of schizophrenia patients.

These investigators have compared current neuropsychological function among these schizophrenia subgroups. Inherent in this approach is an assumption that current neuropsychological performance differs as a function of putative IQ trajectory (stable vs. declining over time); otherwise, there would be little point in defining groups in this manner. An alternative - and perhaps more parsimonious - explanation ought to be tested, namely, that the group differences are attributable primarily to current IQ regardless of IQ trajectory over time. Even if the latter explanation were supported, it would not imply that IQ decline in schizophrenia is necessarily unimportant. If we are to shed light on the relevance of IQ decline to the cognitive basis of schizophrenia, however, it is important to clarify what is and is not predicted by IQ decline. The primary goal of the present study was to examine the issue of the inferred effects on neuropsychological performance of IQ decline over time in schizophrenia in a cross-sectional study using the approach developed by Weickert et al. (2000).

There is consistent evidence for lower childhood and adolescent intellectual function measured at a single time point in individuals who later develop schizophrenia compared with their peers (Jones et al., 1994; David et al., 1997; Cannon et al., 2000b; Erlenmeyer-Kimling et al., 2000; Cannon et al., 2002a). Furthermore, there is evidence of decline over time before the onset of psychosis in individuals who later develop schizophrenia-related disorders (Jones et al., 1994; David et al., 1997; Kremen et al., 1998). Longitudinal studies comparing pre- and post-morbid IQ are rare. Three such studies reviewed by Heaton and Drexler (1987) did indicate declines, but a study by Russell et al. (1997) did not. Russell et al. (1997) studied patients with relatively low IQ who had available premorbid IQ scores as a result of being referred for treatment in childhood; these results might thus reflect a select group of patients that experienced a good deal of lifelong impairment or that had experienced declines very early in life. In a longitudinal study of a community sample, Seidman et al. (2006) found premorbid IQ deficits in those who developed schizophrenia as well as a post-morbid decline of about 10 points about 28 years later; however, it is not known when the decline took place.
Despite some evidence of post-onset decline, there does not appear to be support for the Kraepelinian notion of progressive deterioration; indeed, with the exception of some very persistently treatment-resistant patients (Harvey et al., 1999), there appears to be relative stability or even slight improvements in IQ and other neuropsychological functions after an initial postonset decline (Kurtz, 2005).

The twin method, in the form of the co-twin-control design, provides a powerful addition to these studies of unrelated individuals because the unaffected co-twin serves as an ideal approximation of how the ill twin would perform if not impaired by the illness. Twin data support the existence of premorbid intellectual deficits in schizophrenia but are also consistent with the presence of further post-onset decline. In two twin studies, twins were tested before the onset of psychosis. Reichenberg et al. (2000) and Kremen et al. (2006) examined twin pairs discordant for psychosis, but did not find statistically significant within-pair premorbid cognitive ability differences; however, Kremen et al. (2006) did find significant differences within pairs discordant for schizophrenia specifically. In twin pairs discordant for schizophrenia who were tested long after the onset of illness, nonpsychotic twins did not differ from their ill co-twins on the Wide Range Achievement Test-Revised (WRATR; Jastak and Wilkinson, 1984) — an estimate of premorbid ability - but nonpsychotic twins had about a 10-point higher IQ than their co-twins with schizophrenia (Goldberg et al., 1990). In another twin study of postmorbid functioning (Cannon et al., 2000c), IQ differences between twins with schizophrenia and their nonpsychotic co-twins were also about 10 points. These post-morbid IQ differences were greater than the premorbid cognitive ability difference in the Kremen et al. (2006) study. Taken together, the twin data suggest both premorbid cognitive deficits and post-onset cognitive decline.

\subsection{IQ versus neuropsychological function}

Given that IQ is a composite measure reflecting a subset of neuropsychological ability, a distinction between intellect and neurocognitive function is somewhat arbitrary. On the other hand, there is a long tradition in which IQ is treated as an index of general intellectual ability $(g)$ to distinguish it from other neuropsychological functions because, in general, performance on other neuropsychological tests will tend to be higher when $g$ is higher. Therefore, the distinction still does have some utility.

Multiple neuropsychological impairments have been observed in schizophrenia in the context of roughly 
average or low-average general intellectual functioning (Seidman, 1983; Goldstein, 1986; Braff et al., 1991; Elliot et al., 1998). Even when schizophrenia patients and normal comparison subjects are equated for current IQ levels (Kremen et al., 2001) or when IQ is controlled for statistically (Seidman et al., 2002), patients still perform substantially more poorly on a variety of other neuropsychological measures. Despite the apparent ubiquity of neuropsychological impairment in schizophrenia, roughly a quarter of schizophrenia patients display apparently normal neuropsychological performance (Golden et al., 1982; Silverstein and Zerwic, 1985; Palmer et al., 1997; Kremen et al., 2000; Weickert et al., 2000; Allen et al., 2003). However, even this subgroup may have experienced decline from premorbid levels of cognitive ability (Kremen et al., 2000).

\subsection{IQ trajectories}

In a cross-sectional study, Weickert et al. (2000) measured presumed differences between premorbid and current IQ using the reading subtest of the Wide Range Achievement Test-Revised (WRAT-R; Jastak and Wilkinson, 1984) as an index of premorbid intellectual ability. Based on the idea that individuals with schizophrenia would differ depending on whether or not they had experienced a decline in IQ, they divided schizophrenia patients into three groups: stable and average IQ (preserved); stable and below average IQ (compromised); and IQ decline from premorbid levels (deteriorated). The preserved group had the best neuropsychological performance, but even this group manifested some neuropsychological deficits in executive function and possibly in sustained attention-vigilance. Not surprisingly, neuropsychological impairment was most severe and widespread in the compromised group, with the deteriorated group falling between the preserved and compromised groups. Badcock et al. (2005) utilized the same means of classification and generally found better performance in the preserved group, but nonsignificant differences between the deteriorated and compromised groups. However, none of the groups in the Badcock et al. study differed in processing speed as measured by inspection time. In the former study, current IQ scores were highest in the preserved group, in between in the deteriorated group, and lowest in the compromised group. In the latter study, current IQs were highest in the preserved group, but they were not different in the deteriorated versus the compromised group. This pattern suggests that the difference in most areas of neuropsychological performance among the groups may be more a function of differences in current IQ than of differences in presumed IQ trajectories (i.e., stable vs. declining). In other words, IQ trajectory and current IQ are confounded to the extent that the deteriorated group differs from the others on current IQ.

We addressed the following questions about schizophrenia in the present study: 1) To what extent is current neuropsychological performance associated with current IQ versus presumed decline in IQ from premorbid levels? 2) To what extent are neuropsychological deficits present when IQ is presumed to be preserved? 3) Are putative IQ declines accounted for equally by verbal IQ (VIQ) and performance IQ (PIQ)?

\section{Methods}

Portions of the study methods have been described in detail elsewhere (Faraone et al., 1995; Kremen et al., 1995, 2000; Seidman et al., 2002).

\subsection{Participants}

Patients were recruited from three Boston area hospitals. They were required to have a DSM-III-R diagnosis of schizophrenia (American Psychiatric Association, 1987). Control participants were recruited from nonprofessional hospital staff and advertisements in the community. Controls were required to have no family history of psychosis and no psychopathology (although history of substance use disorders was permitted). Otherwise, study inclusion/exclusion criteria were the same for patients and control participants. These criteria were as follows: age 18 or older; English as the primary language; at least 8 years of formal education; no neurologic disease or damage; no current substance abuse (within the past 6 months); no history of head injury with loss of consciousness greater than $5 \mathrm{~min}$ or with documented neurocognitive sequelae; no mental retardation (IQ $<70)$; and no medical illnesses that may be associated with significant neurocognitive impairment.

Most of the participants in the present study were also the subject of prior reports (Fucetola et al., 2000; Kremen et al., 2000; Seidman et al., 2002). There were 93 controls and 80 patients. All participants gave informed consent and were paid to participate.

\subsection{Procedures and instruments}

\subsubsection{Assessment of psychopathology}

Consensus lifetime DSM-III-R diagnoses for patients were determined on the basis of interviews conducted with the Schedule for Affective Disorders and Schizophrenia 
(SADS) (Endicott and Spitzer, 1978), medical record reviews, and consultation with treating clinicians. In place of the interview, controls were screened for current psychopathology with a short form of the Minnesota Multiphasic Personality Inventory (Vincent et al., 1984) and were excluded if any clinical or validity T-scale, except Masculinity-Femininity, was above 70.

\subsubsection{Neuropsychological assessment}

We administered a battery of tests assessing multiple domains of cognitive function (Table 1). Patients were tested when judged by clinical staff who were familiar with them to be relatively stable clinically (i.e., at their clinical baseline).

\subsubsection{Current $I Q$}

Only 61 patients and 25 controls were administered all 11 Wechsler Adult Intelligence Scale-Revised (WAIS-R) (Wechsler, 1981) subtests, but all participants in the present study had age-scaled scores for the Vocabulary, Digit Span, Block Design, and Digit Symbol subtests. To create a current IQ score, we regressed full scale IQ (FSIQ) scores on the age-scaled scores for these four subtests in the subgroup of participants who had undergone the complete WAIS-R. Separate regression analyses were performed for patients and controls because different subtests might have different weightings in these two groups. Linear regressions provided excellent estimates of FSIQ $\left(R^{2}=0.86\right.$ for patients, $F(4,56)=85.09, R^{2}=0.91$ for controls, $\left.F(4,20)=48.33, \quad P_{\mathrm{s}}<0.0001\right)$. Regression weights from each analysis were used to generate FSIQ scores for patients and controls, respectively. We performed parallel analyses with Verbal (Vocabulary, Digit Span) and Performance (Block Design, Digit Symbol) subtests separately to generate VIQ and PIQ scores, respectively $\left(0.79<R^{2}<0.86\right)$.

\subsubsection{Expected/premorbid IQ}

As in the study of Weickert et al. (2000), expected or premorbid IQ was based on the standard score of the WRAT-R Reading subtest. Reading scores are commonly similar in patients and controls, even though IQ is almost always significantly lower in patients (Dalby and Williams, 1986; Goldberg et al., 1995; Kremen et al., 1996). Based on these considerations, premorbid to post-onset IQ decline was inferred on the basis of WRATR-Reading-FSIQ differences. Given the fact that many schizophrenia patients have neurodevelopmental impairments prior to onset of psychosis (Fish et al., 1965; Feinberg, 1982; Weinberger, 1987; Seidman, 1990) and manifest cognitive impairments prior to onset (Zammit et al., 2004; Kremen et al., 2006; Seidman et al., 2006), the notion of a premorbid period may be imprecise. We use the term "premorbid IQ" as a kind of shorthand; it is perhaps most accurate to think of WRAT-R Reading as an estimate of general intellectual potential had a given individual not been predisposed to develop schizophrenia.

Table 1

Neuropsychological test battery

\begin{tabular}{|c|c|}
\hline $\begin{array}{l}\text { Neuropsychological } \\
\text { function }\end{array}$ & Tests and scores \\
\hline Verbal fluency & $\begin{array}{l}\text { FAS Test (Benton, 1967) Phonemic=average number of words beginning with F, A, S. Semantic=number of words } \\
\text { belonging to the category "animals" }\end{array}$ \\
\hline $\begin{array}{l}\text { General visual-spatial } \\
\text { ability }\end{array}$ & $\begin{array}{l}\text { Judgment of Line Orientation (Benton et al., 1983)* Hooper Visual Organization Test (Hooper, 1983)* Rey-Osterrieth } \\
\text { Complex Figure copy (Rey, 1941) }\end{array}$ \\
\hline $\begin{array}{l}\text { Verbal declarative } \\
\text { memory }^{\text {a }}\end{array}$ & $\begin{array}{l}\text { Wechsler Memory Scale — Form } 1 \text { (WMS) (Wechsler, 1945) or Wechsler Memory Scale — Revised (WMS-R) (Wechsler, } \\
\text { 1987) logical memories \% recalled on immediate and delayed recall, * and savings score (immediate/delayed } \times 100)\end{array}$ \\
\hline Abstraction-Executive & $\begin{array}{l}\text { Wisconsin Card Sorting Test perseverations and categories (Grant and Berg, 1948; Heaton, 1981) * Visual-verbal test total } \\
\text { misses (Feldman and Drasgow, 1981)* }\end{array}$ \\
\hline Executive motor & Manual Position Sequencing total correct (Luria, 1980)* Graphic Sequencing total score and perseverations (Luria, 1980)* \\
\hline $\begin{array}{l}\text { Perceptual-motor } \\
\text { speed }\end{array}$ & Trail Making Test Parts A and B time in seconds (War Department, 1944)* \\
\hline $\begin{array}{l}\text { Mental control- } \\
\text { encoding }\end{array}$ & Wide Range Achievement Test-Revised Arithmetic (Jastak and Wilkinson, 1984) * \\
\hline $\begin{array}{l}\text { Sustained attention- } \\
\text { vigilance }\end{array}$ & $\begin{array}{l}\text { Auditory Continuous Performance Test correct hits (Weintraub and Mesulam, 1985) * Dichotic Listening Test digits } \\
\text { detected (regardless of ear of report accuracy) and digits correct (based on ear of report) (Kimura, 1967)* }\end{array}$ \\
\hline
\end{tabular}




\subsubsection{Definition of schizophrenia subgroups}

Patients were assigned to one of the following three groups according to the classification used by Weickert et al. (2000): 1) The preserved group included patients with average (normal range) premorbid IQ based on WRAT-R Reading without evidence of decline (Reading $\geq 90$ and Reading-IQ difference $<10$ ). 2) The compromised group included patients with below average premorbid IQ without evidence of decline (Reading $<90$ and Reading-IQ difference <10). 3) The deteriorated group included patients with evidence of decline from premorbid level of functioning (Reading-IQ difference $\geq 10$, regardless of absolute score on either measure).

Dichotomizing groups in terms of IQ stability (stable vs. declining) and premorbid IQ level (average vs. below average) yielded four potential cells. In our study, as in the other studies using this classification, what would have been a declining-below average group and a declining-average group were combined. Only two of the 40 deteriorated patients in the present study had premorbid IQs below 90. Consequently, we compared three rather than four patient groups. Given that the premorbid IQ of this deteriorated group was solidly average in each of the studies using this approach, it may be that very few schizophrenia patients who start with below average IQ also manifest an IQ decline. Alternatively, floor effects (e.g., regression to the mean) might make it difficult to detect such patients.

We did not include controls in these subgroup classifications because our interest was in comparing putative IQ trajectories in schizophrenia. Moreover, only $6 \%$ of the controls would have been classified as deteriorated, suggesting that large Reading-IQ discrepancies are rare in 10 psychiatrically healthy individuals. This percentage was highly significantly different from the $50 \%$ of patients in the deteriorated group $\left(\chi^{2}=41.78, d f=1, P<0.0001\right)$.

\subsection{Statistical analysis}

Continuous variables were compared with analysis of variance (ANOVA). Significant ANOVAs were followed up with pairwise comparisons based on Fisher's least significant difference (LSD) test. As expected, current IQ was significantly different between the deteriorated and preserved groups (see Section 3). Current IQ was also significantly different between the control and the deteriorated groups, although each of these was close to the general population average of 100 . To examine differences specifically on the basis of current IQ - as opposed to IQ trajectory - we performed a second set of analyses in which there were equivalent current IQs in these three groups (referred to as FSIQ-matched groups). To achieve this equivalence, we removed controls with the highest IQs and deteriorated patients with the lowest IQs until group means were equivalent to those of the preserved patients. Patients were omitted from the deteriorated rather than the preserved group because the former was a larger group than the latter. Participants were removed in descending or ascending order of IQ without knowledge of any of their other data. This process ensured unbiased selection for these analyses. It also resulted in removal of the two deteriorated patients with below average premorbid IQs.

To provide an additional comparison with our previous work and to account for the potential influence of some demographic variables, the subsamples in which the three groups (control, preserved, deteriorated) were equated for current IQ were also compared on seven composite neuropsychological function scores that we have reported on in previous work (Kremen et al., 2001). These include the functions shown in Table 1, except for verbal fluency. Function scores were the mean of standardized residual scores for tests comprising that function; the direction of some individual scores was changed so that higher scores always reflected better performance. Regression equations based on controls only were used to predict neuropsychological test scores, given an individual's age, sex, and parental education. Regression weights for these variables, derived on the basis of the control group only, were then used to generate predicted scores for both patients and controls. Standardized residual (observed minus predicted) scores were used in these analyses.

To account for potentially misleading results derived from ANOVAs with unequal sample sizes, we used general linear models for unbalanced designs in which adjusted (least squares) means are tested (Freund et al., 1986). Sample sizes also vary for some analyses because data for approximately $3 \%$ of the measures were missing (see Tables). In order to facilitate direct comparisons of neuropsychological results based on different sample sizes, effect sizes were computed by means of Cohen's (1988) $d$. Categorical variables were compared with $\chi^{2}$ statistics. All tests were two-tailed.

\section{Results}

\subsection{Entire sample}

\subsubsection{Demographic and clinical characteristics}

Slightly more than a quarter $(27.5 \%)$ of the patients were in the preserved group, half were in the deteriorated group $(50 \%)$, and nearly a quarter $(22.5 \%)$ were in the 
compromised group. As shown in Table 2, current IQs were significantly different among all groups. The lower FSIQ of the deteriorated group compared with controls or the preserved group was accounted for primarily by PIQ differences. Premorbid IQs, based on WRAT-R Reading, were significantly different among all groups except for controls and preserved group patients. Reading scores were highest in deteriorated patients and lowest in compromised patients. Although within-group differences were, by definition, less than 10 points, Reading scores appeared to be lower than FSIQ scores in the compromised group. The groups were not significantly different in age or parental education. There were some significant differences in education, but deteriorated and preserved groups did not differ. Antipsychotic medication dosage, length of illness, and symptom ratings did not differ among patient groups, but age of first psychiatric hospitalization was significantly earlier in the compromised group than in the other patient groups.

\subsubsection{Neuropsychological performance}

Overall group differences were highly significant for all neuropsychological measures (see Table 3). Pairwise comparisons revealed that controls performed significantly better than each of the patient groups on almost all neuropsychological measures. The exception was that controls and preserved patients did not differ significantly in verbal fluency (semantic, phonemic), visual-spatial ability (Line Orientation, Rey-Osterrieth copy), verbal

Table 2

Demographic and clinical characteristics in normal controls and in schizophrenia patients with and without presumed IQ decline (entire sample)

\begin{tabular}{|c|c|c|c|c|c|c|c|}
\hline \multirow[b]{3}{*}{ Characteristic } & \multirow{3}{*}{$\begin{array}{l}\begin{array}{l}\text { Normal controls } \\
(n=93)\end{array} \\
\text { Mean (S.D.) }\end{array}$} & \multicolumn{3}{|c|}{ Schizophrenia patients } & \multirow[b]{3}{*}{$F$-test } & \multirow[b]{3}{*}{$\begin{array}{l}\text { Pairwise } \\
\text { comparisons }^{\text {a }}\end{array}$} & \multirow[b]{3}{*}{$\begin{array}{l}\text { Effect sizes } \\
(2 \text { vs. } 3)^{b}\end{array}$} \\
\hline & & $\begin{array}{l}\text { Preserved } \\
(n=22)\end{array}$ & $\begin{array}{l}\text { Deteriorated } \\
(n=40)\end{array}$ & $\begin{array}{l}\text { Compromised } \\
(n=18)\end{array}$ & & & \\
\hline & & Mean (S.D.) & Mean (S.D.) & Mean (S.D.) & & & \\
\hline Current FSIQ & $105.1(12.8)$ & $98.4(8.9)$ & $90.9(9.2)$ & $81.9(7.5)$ & 0.0001 & $1>2>3>4$ & 0.82 \\
\hline Current VIQ & $105.6(13.2)$ & $100.6(12.3)$ & $97.2(10.5)$ & $84.0(7.4)$ & 0.0001 & $1>3>4 ; 2>4$ & 0.31 \\
\hline Current PIQ & $104.0(11.7)$ & $94.8(7.3)$ & $84.3(8.3)$ & $81.3(7.9)$ & 0.0001 & $1>2>3,4$ & 1.33 \\
\hline VIQ-PIQ difference & $1.5(13.1)$ & $5.8(12.2)$ & $12.2(12.9)$ & $9.4(2.7)$ & 0.0001 & $3>2,4,1$ & -0.50 \\
\hline Premorbid $\mathrm{IQ}^{\mathrm{c}}$ & $102.1(13.4)$ & $103.2(8.0)$ & $109.7(9.7)$ & $75.7(9.6)$ & 0.0001 & $3>2,1>4$ & -0.71 \\
\hline Age & $42.2(15.3)$ & $44.0(12.8)$ & $45.8(11.4)$ & $37.2(11.0)$ & 0.17 & & 0.15 \\
\hline Education & $13.5(2.5)$ & $12.4(2.0)$ & $12.6(2.3)$ & $10.3(1.5)$ & 0.0001 & $1>3,2>4$ & -0.09 \\
\hline Parental education $^{\mathrm{d}}$ & $10.9(2.2)$ & $12.0(3.0)$ & $11.7(3.0)$ & $10.9(2.3)$ & 0.17 & & 0.10 \\
\hline $\begin{array}{l}\text { Age of first psychiatric } \\
\text { hospitalization }^{\mathrm{d}}\end{array}$ & - & $25.9(6.0)$ & $25.3(6.8)$ & $19.9(4.5)$ & 0.005 & $2,3>4$ & 0.09 \\
\hline $\begin{array}{l}\text { Length of illness } \\
(y r s .)^{d}\end{array}$ & - & $18.6(11.2)$ & $20.9(11.0)$ & $18.7(12.4)$ & 0.69 & & 0.21 \\
\hline $\begin{array}{l}\text { Antipsychotic } \\
\text { medication } \\
\text { d, e }\end{array}$ & - & $539.5(391.5)$ & $536.5(484.6)$ & 777.8 (768.9) & 0.27 & & 0.01 \\
\hline \multicolumn{8}{|l|}{ Symptoms $\mathrm{d}, \mathrm{f}$} \\
\hline Negative & - & $1.8(1.1)$ & $1.7(0.9)$ & $2.0(1.4)$ & 0.71 & - & -0.10 \\
\hline Reality distortion & - & $1.8(1.6)$ & $2.3(1.3)$ & $2.1(1.7)$ & 0.60 & - & 0.36 \\
\hline \multirow[t]{2}{*}{ Disorganization } & - & $1.1(1.0)$ & $1.3(1.1)$ & $1.3(0.8)$ & 0.79 & - & 0.18 \\
\hline & $n(\%)$ & $n(\%)$ & $n(\%)$ & $n(\%)$ & $\chi^{2}$ & - & - \\
\hline Sex $(\text { females })^{g}$ & $50(54.4)$ & $8(36.4)$ & $8(20.0)$ & $2(11.1)$ & 0.0001 & - & - \\
\hline
\end{tabular}

$\mathrm{FSIQ}=$ Full Scale IQ; VIQ= Verbal IQ; PIQ=Performance IQ

a 1 =normal controls; $2=$ preserved; $3=$ deteriorated; $4=$ compromised; commas indicate that groups are not significantly different from one another.

${ }^{\mathrm{b}}$ Effect sizes presented for groups 2 versus 3 only; positive values indicate that group 2 has the higher or less pathological score; negative values indicate that group 3 has the higher or less pathological score.

${ }^{\mathrm{c}}$ Based on Wide Range Achievement Test-Revised Reading subtest (Jastak and Wilkinson, 1984).

d Ns vary due to missing data.

e Dosage in mg. Chlorpromazine equivalents.

${ }^{\mathrm{f}}$ Based on the Scale for the Assessment of Negative Symptoms (SANS) (Andreasen, 1983) and the Scale for the Assessment of Positive Symptoms (SAPS) (Andreasen, 1984); inattention subscale was omitted from the negative symptom dimension because of its redundancy with cognitive function.

${ }^{\mathrm{g}}$ Mantel-Haenszel $\chi^{2}=20.60, d f=1, P<0.0001$ indicates significant trend across groups; for patients only, $\chi^{2}=3.91, d f=2, P=0.15$. 
Table 3

Neuropsychological performance in normal controls and in schizophrenia patients with and without presumed IQ decline (entire sample)

\begin{tabular}{|c|c|c|c|c|c|c|c|}
\hline \multirow[b]{3}{*}{$\begin{array}{l}\text { Neuropsychological function/ } \\
\text { measure }\end{array}$} & \multirow{3}{*}{$\begin{array}{l}\begin{array}{l}\text { Normal controls } \\
(n=93)\end{array} \\
\text { Mean (S.D.) }\end{array}$} & \multicolumn{3}{|c|}{ Schizophrenia patients } & \multirow[b]{3}{*}{$F$-test } & \multirow[b]{3}{*}{$\begin{array}{l}\text { Pairwise } \\
\text { comparisons }^{a}\end{array}$} & \multirow[b]{3}{*}{$\begin{array}{l}\text { Effect sizes } \\
(2 \text { vs. } 3)^{b}\end{array}$} \\
\hline & & \multirow{2}{*}{$\begin{array}{l}\text { Preserved } \\
(n=22) \\
\text { Mean (S.D.) }\end{array}$} & \multirow{2}{*}{$\begin{array}{l}\begin{array}{l}\text { Deteriorated } \\
(n=40)\end{array} \\
\text { Mean (S.D.) }\end{array}$} & \multirow{2}{*}{$\begin{array}{l}\text { Compromised } \\
(n=18) \\
\text { Mean (S.D.) }\end{array}$} & & & \\
\hline & & & & & & & \\
\hline \multicolumn{8}{|l|}{ Verbal fluency } \\
\hline Phonemic $^{c}$ & $13.6(3.8)$ & $12.0(4.5)$ & $10.1(3.9)$ & $8.4(3.1)$ & 0.0001 & $1,2>3,4$ & 0.46 \\
\hline Semantic $^{c}$ & $18.9(4.8)$ & $16.9(5.2)$ & $14.0(3.9)$ & $11.3(4.4)$ & 0.0001 & $1,2>3>4$ & 0.66 \\
\hline \multicolumn{8}{|l|}{ Visual-spatial } \\
\hline Line orientation $^{\mathrm{c}}$ & $24.4(4.3)$ & $25.8(3.8)$ & $23.0(5.4)$ & $19.4(6.2)$ & 0.0007 & $2>3>4 ; 1>4$ & 0.58 \\
\hline Hooper $\mathrm{VOT}^{\mathrm{c}}$ & $26.2(2.7)$ & $23.8(4.2)$ & $22.0(4.9)$ & $22.0(7.0)$ & 0.0001 & $1>2,3,4$ & 0.39 \\
\hline Rey-Osterrieth copy ${ }^{c}$ & $33.1(2.9)$ & $31.4(4.5)$ & $27.8(6.9)$ & $26.5(6.5)$ & 0.0001 & $1,2>3,4$ & 0.59 \\
\hline \multicolumn{8}{|l|}{ Executive-abstraction } \\
\hline WCST categories $^{c}$ & $5.3(1.5)$ & $3.6(2.6)$ & $2.5(2.2)$ & $2.4(2.4)$ & 0.0001 & $1>2,3,4 ; 2>3$ & 0.48 \\
\hline WCST perseverations $^{\mathrm{c}}$ & $9.8(11.4)$ & $36.0(43.7)$ & $46.1(38.1)$ & $58.2(50.1)$ & 0.0001 & $4>2>1 ; 3>1$ & 0.25 \\
\hline Visual-verbal test ${ }^{\mathrm{c}}$ & $13.7(6.5)$ & $26.2(12.2)$ & $29.2(13.1)$ & $32.9(15.5)$ & 0.0001 & $4,3,2>1,4>2$ & 0.23 \\
\hline \multicolumn{8}{|l|}{ Verbal memory } \\
\hline $\begin{array}{l}\text { Logical memories } \\
\text { immediate }\end{array}$ & $59.2(12.0)$ & $45.4(19.2)$ & $38.4(18.5)$ & $29.3(17.3)$ & 0.0001 & $\begin{array}{l}1>2,3,4 ; 2>4 \\
3>4\end{array}$ & 0.37 \\
\hline $\begin{array}{l}\text { Logical memories } \\
\text { delayed }\end{array}$ & $51.2(13.9)$ & $38.0(17.5)$ & $28.6(17.2)$ & $20.8(15.2)$ & 0.0001 & $1>2>3,4$ & 0.54 \\
\hline Savings score & $85.8(13.5)$ & $82.1(20.4)$ & $69.2(24.1)$ & $69.7(29.3)$ & 0.0001 & $1,2>3,4$ & 0.56 \\
\hline \multicolumn{8}{|l|}{ Mental control-encoding } \\
\hline WRAT-R arithmetic ${ }^{c}$ & $96.6(15.7)$ & $95.6(12.8)$ & $90.7(13.6)$ & $75.0(11.7)$ & 0.0001 & $1>3,4 ; 2>4,3>4$ & 0.37 \\
\hline \multicolumn{8}{|l|}{ Perceptual-motor } \\
\hline Trails $\mathrm{A}^{\mathrm{c}}$ & $28.7(12.4)$ & $39.7(14.2)$ & $55.6(29.9)$ & $60.0(45.9)$ & 0.0001 & $4,3>2>1$ & 0.66 \\
\hline Trails $\mathrm{B}^{\mathrm{c}}$ & $69.6(33.8)$ & $109.3(58.4)$ & $157.8(106.4)$ & $161.9(97.3)$ & 0.0001 & $4,3>2>1$ & 0.54 \\
\hline \multicolumn{8}{|l|}{ Executive-motor } \\
\hline Manual position & $23.8(3.9)$ & $19.2(8.1)$ & $16.1(9.0)$ & $17.0(8.4)$ & 0.0001 & $1>2,4,3$ & 0.36 \\
\hline \multicolumn{8}{|l|}{ Sequencing ${ }^{c}$} \\
\hline Graphic sequencing $^{c}$ & $0.8(0.8)$ & $1.3(1.1)$ & $1.2(0.9)$ & $1.7(1.1)$ & 0.0009 & $4>3,1 ; 2>1$ & -0.10 \\
\hline \multicolumn{8}{|l|}{$\begin{array}{l}\text { Sustained attention- } \\
\text { vigilance }\end{array}$} \\
\hline $\mathrm{CPT}^{\mathrm{c}}$ & $29.0(1.3)$ & $26.6(3.5)$ & $25.1(5.4)$ & $24.2(4.8)$ & 0.0001 & $1>2,3,4 ; 2>4$ & 0.31 \\
\hline Dichotic digits correct ${ }^{c}$ & $205.4(40.7)$ & $191.8(44.6)$ & $164.9(62.7)$ & $155.7(45.6)$ & 0.0001 & $1>3,4 ; 2>4$ & 0.48 \\
\hline Dichotic digits detected ${ }^{\mathrm{c}}$ & $231.6(37.3)$ & $226.3(30.7)$ & $200.8(54.5)$ & $205.0(24.3)$ & 0.0002 & $1>4,3 ; 2>3$ & 0.56 \\
\hline
\end{tabular}

a $1=$ normal controls; 2 =preserved; $3=$ deteriorated; $4=$ compromised; commas indicate that groups are not significantly different from one another.

${ }^{\mathrm{b}}$ Effect sizes presented for groups 2 versus 3 only; positive values indicate that group 2 has the higher or less pathological score; negative values indicate that group 3 has the higher or less pathological score.

c $N$ s vary due to missing data.

memory (savings), mental control-encoding (Arithmetic), and attention-vigilance (dichotic listening).

The preserved patient group performed significantly better than the deteriorated or compromised group in verbal fluency (semantic, phonemic), visual-spatial ability (Line Orientation, Rey-Osterrieth copy), verbal memory (Logical Memories delayed, savings score), and perceptual-motor speed (Trail Making Test A and B).

The performance of the deteriorated group was, in turn, significantly better than that of the compromised group in verbal fluency (semantic), visual-spatial ability (Line Orientation), abstraction-executive (WCST categories), verbal memory (Logical Memories immediate), mental control-encoding (Arithmetic), and executive motor (graphic sequencing, manual position sequencing). Some of these comparisons might be misleading owing to differences in sample sizes across groups. For example, the preserved group achieved slightly more WCST categories than the deteriorated group; however, the deteriorated group, but not the preserved group, was significantly better than the compromised group on WCST categories. This paradoxical result occurred because of the greater power afforded by the larger sample size of the deteriorated group compared with the 
preserved group. Indeed, the effect sizes for these two comparisons were almost identical. Because the differences of greatest interest in the present study are those between the preserved and deteriorated groups, Tables $2-$ 5 show effect sizes $(d)$ for those comparisons. The average $d$ in Table 3 is 0.43 , indicating a medium effect size with better performance in the preserved group than in the compromised group. These effects tended to be fairly consistent across different neurocognitive functions.

\subsection{FSIQ-matched groups}

This section refers to analyses comparing groups in which controls, preserved patients, and deteriorated patients were matched for group mean current IQ (FSIQ).

\subsubsection{Demographic and clinical characteristics}

Table 4 shows that the aforementioned groups were now well matched on FSIQ. As in the full sample, the deteriorated group had a significantly greater VIQ-PIQ difference than the other groups. Owing to the way in which the groups were defined, premorbid IQ was now substantially higher in the deteriorated group than in any of the other groups, with a very large $d$ of 1.72 for the comparison with preserved patients. There were no other substantial changes with regard to group differences in other demographic or clinical characteristics.

\subsubsection{Neuropsychological performance}

Almost all of the overall group differences were again highly significant for the neuropsychological

Table 4

Demographic and clinical characteristics in normal controls and in schizophrenia patients with and without presumed IQ decline (control, preserved, and deteriorated groups equated for current IQ)

\begin{tabular}{|c|c|c|c|c|c|c|c|}
\hline \multirow[b]{3}{*}{ Characteristic } & \multirow[b]{2}{*}{$\begin{array}{l}\text { Normal controls } \\
(n=66)\end{array}$} & \multicolumn{3}{|c|}{ Schizophrenia patients } & \multirow[b]{3}{*}{$F$-test } & \multirow[b]{3}{*}{$\begin{array}{l}\text { Pairwise } \\
\text { comparisons }^{\text {a }}\end{array}$} & \multirow[b]{3}{*}{$\begin{array}{l}\text { Effect sizes } \\
(2 \text { vs. } 3)^{b}\end{array}$} \\
\hline & & $\begin{array}{l}\text { Preserved } \\
(n=22)\end{array}$ & $\begin{array}{l}\text { Deteriorated } \\
(n=21)\end{array}$ & $\begin{array}{l}\text { Compromised } \\
(n=18)\end{array}$ & & & \\
\hline & Mean (S.D.) & Mean (S.D.) & Mean (S.D.) & Mean (S.D.) & & & \\
\hline Current IQ & $98.4(7.6)$ & $98.4(8.9)$ & $97.6(5.7)$ & $81.9(7.5)$ & 0.0001 & $1,2,3>4$ & 0.10 \\
\hline Current VIQ & $99.1(8.1)$ & $100.6(12.3)$ & $103.8(7.6)$ & $84.0(7.4)$ & 0.0001 & $3>1,4 ; 2>4$ & -0.32 \\
\hline Current PIQ & $100.0(9.4)$ & $94.8(7.3)$ & $89.6(7.3)$ & $81.3(7.9)$ & 0.0001 & $1>2,3>4$ & 0.71 \\
\hline VIQ-PIQ difference & $-0.9(11.5)$ & $5.8(12.2)$ & $14.2(11.0)$ & $9.4(2.7)$ & 0.0001 & $3>2,4,1 ; 2>1$ & -0.72 \\
\hline Premorbid $\mathrm{IQ}^{\mathrm{c}}$ & $97.3(12.4)$ & $103.2(8.0)$ & $114.9(5.5)$ & $75.7(9.6)$ & 0.0001 & $3>2>1>4$ & -1.72 \\
\hline Age & $41.2(14.9)$ & $44.0(12.8)$ & $47.0(11.8)$ & $37.2(11.0)$ & 0.13 & & 0.24 \\
\hline Education & $13.0(2.4)$ & $12.4(2.0)$ & $13.6(2.0)$ & $10.3(1.5)$ & 0.0001 & $3,1,2>4$ & -0.60 \\
\hline Parental education $^{\mathrm{d}}$ & $10.7(2.3)$ & $12.0(3.0)$ & $12.0(2.9)$ & $10.9(2.3)$ & 0.08 & & 0.00 \\
\hline $\begin{array}{l}\text { Age of first psychiatric } \\
\text { hospitalization }^{\mathrm{d}, \mathrm{e}}\end{array}$ & & $25.9(6.0)$ & $27.1(7.9)$ & $19.9(4.5)$ & 0.003 & $3,2>4$ & -0.17 \\
\hline 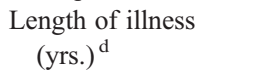 & & $18.6(11.2)$ & $20.4(12.6)$ & $18.7(12.4)$ & 0.87 & - & 0.15 \\
\hline $\begin{array}{l}\text { Antipsychotic } \\
\text { medication }^{\text {d, e }}\end{array}$ & - & $539.5(391.5)$ & $540.5(489.0)$ & 777.8 (768.9) & 0.34 & - & 0.002 \\
\hline \multicolumn{8}{|l|}{ Symptoms ${ }^{\mathrm{d}, \mathrm{f}}$} \\
\hline Negative & - & $1.8(1.1)$ & $1.6(1.0)$ & $2.0(1.4)$ & 0.67 & & -0.17 \\
\hline Reality distortion & - & $1.8(1.6)$ & $2.3(1.2)$ & $2.1(1.7)$ & 0.66 & - & 0.36 \\
\hline \multirow[t]{2}{*}{ Disorganization } & - & $1.1(1.0)$ & $1.2(1.1)$ & $1.3(0.8)$ & 0.88 & - & 0.09 \\
\hline & $n(\%)$ & n $(\%)$ & $n(\%)$ & $n(\%)$ & $\chi^{2}$ & - & - \\
\hline Sex $(\text { females })^{g}$ & $35(53.0)$ & $8(36.4)$ & $5(23.8)$ & $2(11.1)$ & 0.004 & - & - \\
\hline
\end{tabular}

$\mathrm{FSIQ}=$ Full Scale IQ; VIQ= Verbal IQ; PIQ=Performance IQ

a $1=$ normal controls; 2 =stable-below-average; 3=IQ-decline; 4=stable-below-average; commas indicate that groups are not significantly different from one another.

${ }^{\mathrm{b}}$ Effect sizes presented for groups 2 versus 3 only; positive value indicates that group 2 has the higher or less pathological score; negative value indicates that group 3 has the higher or less pathological score.

c Based on Wide Range Achievement Test-Revised Reading subtest (Jastak and Wilkinson, 1984).

d Ns vary due to missing data.

e Dosage in mg. Chlorpromazine equivalents.

${ }^{\mathrm{f}}$ Based on the Scale for the Assessment of Negative Symptoms (SANS) (Andreasen, 1983) and the Scale for the Assessment of Positive Symptoms (SAPS) (Andreasen, 1984); inattention subscale was omitted from the negative symptom dimension because of its redundancy with cognitive function.

${ }^{\mathrm{g}}$ Mantel-Haenszel $\chi^{2}=13.23, d f=1, P<0.0003$ indicates significant trend across groups; for patients only, $\chi^{2}=3.42, d f=2, P=0.19$. 
Table 5

Neuropsychological performance in normal controls and in schizophrenia patients with and without presumed IQ decline (control, preserved, and deteriorated groups equated for current IQ)

\begin{tabular}{|c|c|c|c|c|c|c|c|}
\hline \multirow[b]{3}{*}{$\begin{array}{l}\text { Neuropsychological function/ } \\
\text { measure }\end{array}$} & \multirow{3}{*}{$\begin{array}{l}\begin{array}{l}\text { Normal controls } \\
(n=66)\end{array} \\
\text { Mean (S.D.) }\end{array}$} & \multicolumn{3}{|c|}{ Schizophrenia patients } & \multirow[b]{3}{*}{$F$-test } & \multirow[b]{3}{*}{$\begin{array}{l}\text { Pairwise } \\
\text { comparisons }^{\mathrm{a}}\end{array}$} & \multirow[b]{3}{*}{$\begin{array}{l}\text { Effect sizes } \\
(2 \text { vs. } 3)^{\mathrm{b}}\end{array}$} \\
\hline & & $\begin{array}{l}\text { Preserved } \\
(n=22)\end{array}$ & $\begin{array}{l}\text { Deteriorated } \\
(n=21)\end{array}$ & $\begin{array}{l}\text { Compromised } \\
(n=18)\end{array}$ & & & \\
\hline & & Mean (S.D.) & Mean (S.D.) & Mean (S.D.) & & & \\
\hline \multicolumn{8}{|l|}{ Verbal fluency } \\
\hline Phonemic ${ }^{c}$ & $13.0(3.5)$ & $12.0(4.5)$ & $11.3(3.9)$ & $8.4(3.1)$ & 0.0002 & $1,2,3>4$ & 0.17 \\
\hline Semantic $^{c}$ & $18.1(4.8)$ & $16.9(5.2)$ & $16.1(2.7)$ & $11.3(4.4)$ & 0.0001 & $1,2,3>4$ & 0.20 \\
\hline \multicolumn{8}{|l|}{ Visual-spatial } \\
\hline Line orientation ${ }^{\mathrm{c}}$ & $23.4(4.6)$ & $25.8(3.8)$ & $24.4(3.3)$ & $19.4(6.2)$ & 0.002 & $2,3,1>4$ & 0.39 \\
\hline Hooper $\mathrm{VOT}^{\mathrm{c}}$ & $25.9(2.7)$ & $23.8(4.2)$ & $22.6(4.7)$ & $22.0(7.0)$ & 0.002 & $1>2,3,4$ & 0.27 \\
\hline Rey-Osterrieth copy ${ }^{\mathrm{c}}$ & $32.9(2.9)$ & $31.4(4.5)$ & $30.4(4.7)$ & $26.5(6.5)$ & 0.0001 & $1>3,4 ; 2,3>4$ & 0.22 \\
\hline \multicolumn{8}{|l|}{ Executive-abstraction } \\
\hline WCST categories $^{\mathrm{c}}$ & $5.0(1.7)$ & $3.6(2.6)$ & $3.3(2.3)$ & $2.4(2.4)$ & 0.0001 & $1>2,3,4$ & 0.12 \\
\hline WCST perseverations $^{c}$ & $12.5(12.4)$ & $36.0(43.7)$ & $37.3(36.0)$ & $58.2(50.1)$ & 0.0001 & $4>3,2>1$ & 0.03 \\
\hline Visual-verbal test ${ }^{\mathrm{c}}$ & $14.9(6.9)$ & $26.2(12.2)$ & $22.7(10.6)$ & $32.9(15.5)$ & 0.0001 & $4,>2,3>1$ & -0.31 \\
\hline \multicolumn{8}{|l|}{ Verbal memory } \\
\hline $\begin{array}{l}\text { Logical memories } \\
\text { immediate }\end{array}$ & $57.2(12.1)$ & $45.4(19.2)$ & $46.4(14.8)$ & $29.3(17.3)$ & 0.0001 & $1>, 3,2>4$ & -0.06 \\
\hline Logical memories delayed & $48.8(14.0)$ & $38.0(17.5)$ & $36.3(15.0)$ & $20.8(15.2)$ & 0.0001 & $1>2,3>4$ & 0.10 \\
\hline Savings & $84.6(14.4)$ & $82.1(20.4)$ & $77.1(16.8)$ & $69.7(29.3)$ & 0.02 & $1,2>4$ & 0.27 \\
\hline \multicolumn{8}{|l|}{ Mental control-encoding } \\
\hline WRAT-R arithmetic & $94.2(12.2)$ & $95.6(12.8)$ & $97.4(13.7)$ & $75.0(11.7)$ & 0.0001 & $3,2,1>4$ & -0.14 \\
\hline \multicolumn{8}{|l|}{ Perceptual-motor } \\
\hline Trails $\mathrm{A}^{\mathrm{c}}$ & $29.5(13.2)$ & $39.7(14.2)$ & $47.2(16.6)$ & $60.0(45.9)$ & 0.0001 & $4>2,1 ; 3>1$ & 0.49 \\
\hline Trails B ${ }^{\mathrm{c}}$ & $74.5(37.5)$ & $109.3(58.4)$ & $116.5(58.2)$ & $161.9(97.3)$ & 0.0001 & $4>3,2>1$ & 0.12 \\
\hline Executive-motor & & & & & & & \\
\hline $\begin{array}{l}\text { Manual position } \\
\text { sequencing }\end{array}$ & $23.6(4.3)$ & $19.2(8.1)$ & $18.8(8.5)$ & $17.0(8.4)$ & 0.0003 & $1>2,3,4$ & 0.05 \\
\hline Graphic sequencing & $0.9(0.8)$ & $1.3(1.1)$ & $0.7(0.7)$ & $1.7(1.1)$ & 0.002 & $4>1,3 ; 2>3 ; 3>4$ & -0.67 \\
\hline \multicolumn{8}{|l|}{ Sustained attention-vigilance } \\
\hline $\mathrm{CPT}^{\mathrm{c}}$ & $29.1(1.2)$ & $26.6(3.5)$ & $25.8(4.7)$ & $24.2(4.8)$ & 0.0001 & $1>2,3,4 ; 2>4$ & 0.20 \\
\hline Dichotic digits correct ${ }^{\mathrm{c}}$ & $202.2(38.9)$ & $191.8(44.6)$ & $185.9(54.5)$ & $155.7(45.6)$ & 0.003 & $1>4 ; 2>4$ & 0.12 \\
\hline Dichotic digits detected $^{\mathrm{c}}$ & $231.1(35.1)$ & $226.3(30.7)$ & $219.9(48.2)$ & $205.0(24.3)$ & 0.08 & - & 0.16 \\
\hline
\end{tabular}

a $1=$ normal controls; 2 =preserved; $3=$ deteriorated; $4=$ compromised; commas indicate that groups are not significantly different from one another.

${ }^{\mathrm{b}}$ Effect sizes presented for groups 2 versus 3 only; positive values indicate that group 2 has the higher or less pathological score; negative values indicate that group 3 has the higher or less pathological score.

c $N$ s vary due to missing data.

measures (see Table 5). In contrast to the full sample results, pairwise comparisons revealed only a single significant difference between the preserved and deteriorated groups. This difference was for Graphic Sequencing errors, but it was in the opposite direction of most of the comparisons in that the preserved group had more errors than the deteriorated group. The general lack of significant differences was not due to the reduced sample sizes in these analyses. In stark contrast to the full sample results, the average effect size for these comparisons between the FSIQequated preserved and deteriorated patients was only 0.10 .
Analysis of the composite neuropsychological function scores (which were adjusted for age, sex, and parental education) in the groups that were equated for IQ resulted in highly significant overall differences for each of the seven functions (all $P_{\mathrm{s}}<0.0001$; see Fig. 1). Pairwise comparisons indicated that controls performed significantly better than the preserved group on five composite functions: abstraction-executive; verbal memory; perceptual-motor speed; executive motor ability; and sustained attention-vigilance. Controls performed significantly better than the deteriorated group on four of those five functions: all but executive motor ability. There were no significant differences 


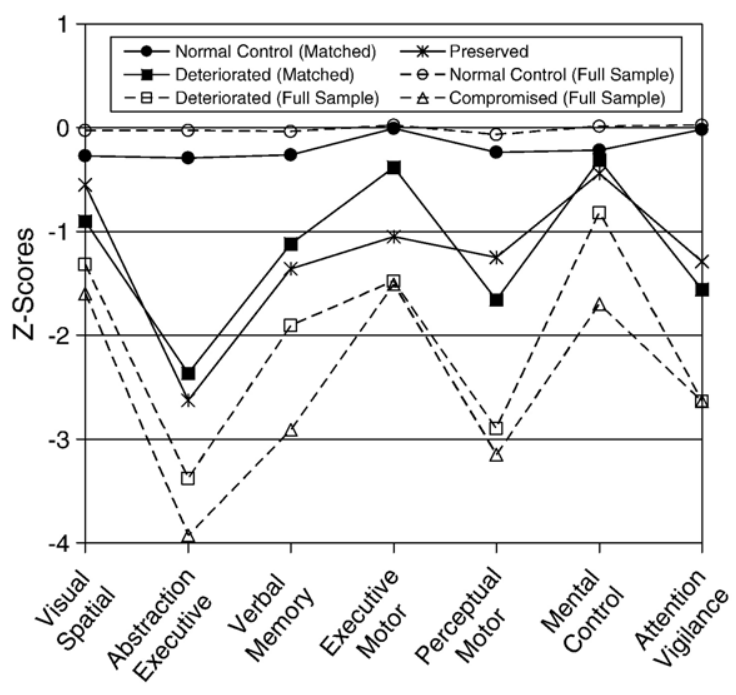

Fig. 1. Neuropsychological profiles of schizophrenia patients and controls. Solid lines/filled markers represent subgroups equated for current IQ (total $n=65$ controls and 40 patients). Dashed lines/unfilled markers represent full sample for each group (total $n=92$ controls and 80 patients). Preserved and compromised group profiles are shown for the full samples only because: 1) controls and deteriorated groups were matched to the full-sample preserved group; and 2) none of the matched-group comparisons included the compromised group.

between the preserved and deteriorated patients on any of the seven composite functions, and only one significant individual score difference ${ }^{1}$.

\section{Discussion}

Patient subgrouping resulted in $27.5 \%$ in the preserved group, $50 \%$ in the deteriorated group, and $22.5 \%$ in the compromised group. This distribution is very similar to that found in the Weickert et al. (2000) study $(24.8 \%, 51.3 \%$, and $23.9 \%$, respectively), but it differs from the Badcock et al. (2005) study (41.3\%, $43.1 \%$, and $15.6 \%$, respectively). Sampling differences may account for the larger preserved and smaller compromised groups in the Badcock et al. (2005) study because it included more outpatients and more paranoid subtype patients than the other two studies. Although the same criteria were used to define groups in all three studies, they differed somewhat in the size of estimated premorbid-current IQ differences within

\footnotetext{
${ }^{1}$ Although these differences were almost all nonsignificant, it may be noted that the direction of differences between the preserved and deteriorated groups did tend to differ in Table 5 versus Fig. 1. The reason for this shift is that Table 5 shows unadjusted comparisons of individual neuropsychological scores whereas Fig. 1 shows age-, sex-, and parental education-adjusted comparisons of composite function scores.
}

groups, and in which groups differed in current FSIQ. Sampling differences, as well as the use of different measures to estimate premorbid and current IQ, may have contributed to such discrepancies.

\subsection{Relationship of presumed IQ trajectory to current neuropsychological performance}

By comparing subsets of individuals from the deteriorated and preserved groups that had equivalent (and average) current IQ, we were able to examine the effect of presumed IQ decline on neuropsychological function unconfounded by differences in current IQ. In this case, both groups had very similar levels of neuropsychological performance. There were no other substantial demographic or clinical characteristics between the groups that might account for the results. If the index of decline (WRAT-R Reading minus FSIQ) is valid, then the preserved and deteriorated groups must have experienced very different IQ trajectories, with the latter experiencing much greater deterioration from premorbid ability levels than the former. Despite the very different presumed IQ trajectories (stable vs. declining), current neuropsychological performance did not differ if current IQs were similar. These results suggest that current neuropsychological strengths and weaknesses in schizophrenia do not differ greatly as a function of IQ trajectory up to that point (i.e., whether or not there were declines in IQ from premorbid levels). Rather, it appears that the more powerful association is simply the tendency for current neuropsychological function to covary with current IQ.

\subsection{Neuropsychological performance in schizophrenia patients with preserved $I Q$}

The present analyses of FSIQ-matched groups suggest that both preserved and deteriorated patients manifested neuropsychological decline relative to their current IQ, but, by definition, only the latter showed a pattern consistent with presumed IQ decline from premorbid levels. Thus, the neurocognitive compromise of schizophrenia might leave IQ essentially unaffected in some cases, with deficiencies restricted to other neuropsychological functions. Paralleling the conclusions of Weickert et al. (2000) and Badcock et al. (2005) that executive function deficits are core cognitive features of schizophrenia, the present results are consistent with the idea that patients in the preserved IQ subgroup manifest a kind of dysexecutive syndrome. This is consistent with the fact that prefrontal cortical lesions can cause significant neuropsychological deficits 
in the absence of substantial IQ decline (Heilman and Valenstein, 1979).

\subsection{Verbal IQ-performance IQ comparisons}

It was also noted that after being equated for current IQ, the deteriorated group still had a significantly larger VIQ-PIQ difference than the preserved group. The fact that decline is somewhat stronger in performance rather than verbal subtests is relatively consistent with earlier IQ findings in schizophrenia (Heaton and Drexler, 1987; Bilder et al., 1992), although it is possible that the larger VIQ-PIQ differences existed premorbidly. For the most part, Tables 3 and 5 indicate that this difference between preserved and deteriorated patients is not related to differential effects for specific neuropsychological functions. However, after matching, the effect size for the difference between these groups on Trails A was 0.49 (Table 5). This raises the possibility that perceptual-motor slowing could play a role in the verbal performance-IQ differences between these groups. On the other hand, this suggestion is tempered by the fact that this was only 1 of 19 comparisons in Table 5, and that Badcock et al. (2005) found no group differences on inspection time, another processing speed measure.

\subsection{Limitations}

Most importantly, cross-sectional analyses do not allow us to be certain that patients in the deteriorated group actually experienced decline. It is possible that large Reading-IQ discrepancies existed premorbidly. Even if we were certain of decline, we cannot be sure whether it began before onset, or early or late in the course of illness. The rationale for our IQ decline index was based, in part, on the assumption that WRAT-R Reading is largely unaffected by schizophrenic illness. Despite strong support for this notion (Dalby and Williams, 1986; Goldberg et al., 1990; Kremen et al., 1995, 1996), some patients may still experience schizophrenia-related reading recognition impairment. In those cases, WRAT-R Reading scores would underestimate premorbid ability and Reading-IQ differences would be reduced; consequently, IQ decline would be underestimated. Analogous concerns have been raised about Reading-IQ discrepancy scores in people with reading disability (Fletcher et al., 1992), although in that case the nature of the problem is reversed. That is, IQ, rather than reading, is assumed to be relatively unaffected.

We estimated IQ from a subset of WAIS-R tests. Use of the complete WAIS-R would have been ideal; however, regression models derived from the subset of participants who were administered the complete test suggest that our estimate has a high degree of accuracy. Differences across studies may, in part, be due to differences in premorbid and current IQ measures. Our measures were more similar to those used by Weickert et al. (2000) than those used by Badcock et al. (2005). It should also be noted that the correlation between WRAT-R Reading and IQ in our sample was 0.73 for controls and 0.66 for patients $\left(P_{\mathrm{S}}<0.0001\right)$. Although highly significant, these associations indicate that WRAT-R Reading (or any other word recognition measure) provides an imperfect estimate of IQ.

It would have been preferable to have used a structured interview instead of the MMPI to assess controls. On the other hand, our previous work suggests that these participants do constitute a reasonable control group (Faraone et al., 1995; Kremen et al., 1996); the present results are consistent with previous results using a similar test battery (Weickert et al., 2000), and the nature of the control group would not affect the key comparisons among the schizophrenia groups. Finally, there were some significant differences in sex ratios across groups in our study. However, these differences were not significant among the schizophrenia patients, and the results held up in comparisons based on composite neuropsychological function scores that were adjusted for sex.

\subsection{Implications}

It is worth clarifying that our conclusion in no way implies that the presence or absence of decline in cognitive function in schizophrenia is inconsequential. However, in order to make inferences about IQ decline, it is important to rule out a simpler explanation based on IQ differences at a single point in time. In previous work, we looked at actual (not estimated) IQ decline in children tested at ages 4 and 7; substantial declines predicted increased risk for psychotic symptoms at age 23 (Kremen et al., 1998). Large declines would tend to mean lower IQs at age 7, so it might just be lower IQ — not IQ decline that predicted later psychotic symptoms. In this instance, IQ decline was a significant predictor even after controlling for IQ at age 7. In contrast, we believe that the results of the present study and the Weickert and Badcock studies suggest that IQ decline does not add much to current IQ as a predictor of current neuropsychological performance in schizophrenia. The outcomes may be different, but it is important to test these two alternatives in both cases. The different neurocognitive trajectories that individuals with schizophrenia experience may also have implications for cognitive or vocational 
rehabilitation. For example, deteriorated intellect might indicate a more severe illness with less ability to improve cognitively. On the other hand, someone with deteriorated intellect, but similar current IQ as someone with preserved intellect, might have more potential for cognitive improvement based on his or her higher level of premorbid ability (cf. Kremen et al., 1994). Greater decline from premorbid levels of function may also be associated with low self-esteem, a need to experience a sense of grieving or mourning with regard to the loss of skills and abilities, and difficulty coming to terms with the resulting change in one's identity. These issues may be an important focus of psychotherapeutic as well as cognitive rehabilitation interventions (Seidman, 1994). In the end, helping to clarify the areas in which IQ decline may or may not make a difference should shed some new light on the cognitive basis of schizophrenia.

\section{Acknowledgments}

We thank Lynda Jacobs and Dr. John Pepple for their contributions to the project. Preparation of this article was supported in part by the National Institute of Mental Health Grants MH43518-01 (MERIT Award) and MH46318, the Veteran's Affairs Medical Research and Health Services Research and Development Programs, and a Distinguished Investigator Award from NARSAD to Dr. Tsuang, NARSAD grants to Drs. Kremen and Seidman, and a Stanley Foundation grant to Dr. Seidman.

\section{References}

Allen, D.N., Goldstein, G., Warnick, E., 2003. A consideration of neuropsychologically normal schizophrenia. Journal of the International Neuropsychological Society 9, 56-63.

American Psychiatric Association, 1987. Diagnostic and Statistical Manual of Mental Disorders, 3rd rev. ed. American Psychiatric Press, Washington, DC.

Andreasen, N.C., 1983. Scale for the Assessment of Negative Symptoms (SANS). University of Iowa, Iowa City.

Andreasen, N.C., 1984. Scale for the Assessment of Positive Symptoms (SAPS). University of Iowa, Iowa City.

Badcock, J.C., Dragovic, M., Waters, F.A., Jablensky, A., 2005. Dimensions of intelligence in schizophrenia: evidence from patients with preserved, deteriorated and compromised intellect. Journal of Psychiatric Research 39, 11-19.

Benton, A.L., 1967. Problems of test construction in the field of aphasia. Cortex 3, 32-58.

Benton, A.L., Hamsher, K., Varney, N.R., Spreen, O., 1983. Contributions to Neuropsychological Assessment. Oxford University Press, New York.

Bilder, R.M., Lipschutz-Broch, L., Reiter, G., Geisler, S.H., Mayerhoff, D.I., Lieberman, J.A., 1992. Intellectual deficits in first-episode schizophrenia: evidence for progressive deterioration. Schizophrenia Bulletin 18, 437-448.
Braff, D.L., Heaton, R., Kuck, J., Cullum, M., Moranville, J., Grant, I., Zisook, S., 1991. The generalized pattern of neuropsychological deficits in outpatients with chronic schizophrenia with heterogeneous Wisconsin Card Sorting Test results. Archives of General Psychiatry 48, 891-898.

Cannon, M., Caspi, A., Moffitt, T.E., Harrington, H., Taylor, A., Murray, R.M., Poulton, R., 2002a. Evidence for early-childhood, pan-developmental impairment specific to schizophreniform disorder. Archives of General Psychiatry 59, 449-456.

Cannon, T.D., Bearden, C.E., Hollister, J.M., Rosso, I.M., Sanchez, L.E., Hadley, T., 2000b. Childhood cognitive functioning in schizophrenia patients and their unaffected siblings: a prospective cohort study. Schizophrenia Bulletin 26, 379-393.

Cannon, T.D., Huttunen, M.O., Lonnqvist, J., Tuulio-Henriksson, A., Pirkola, T., Glahn, D., Finklestein, J., Hietanen, M., Kaprio, J., Koskenvuo, M., 2000c. The inheritance of neuropsychological dysfunction in twins discordant for schizophrenia. American Journal of Human Genetics 67, 369-382.

Cohen, J., 1998. Statistical Power Analysis for the Behavioral Sciences, 2nd ed. Lawrence Erlbaum, Hillsdale, NJ.

Dalby, J.T., Williams, R., 1986. Preserved reading and spelling ability in psychotic disorders. Psychological Medicine 16, 171-175.

David, A.S., Malmberg, A., Brandt, L., Allebeck, P., Lewis, G., 1997. IQ and risk for schizophrenia: a population-based cohort study. Psychological Medicine 27, 1311-1323.

Elliott, R., McKenna, P.J., Robbins, T.W., Sahakian, B.I., 1998. Specific neuropsychological deficits in schizophrenic patients with preserved intellectual function. Cognitive Neuropsychiatry 3, $45-70$.

Endicott, J., Spitzer, R.L., 1978. A diagnostic interview: the Schedule for Affective Disorders and Schizophrenia. Archives of General Psychiatry 35, 837-844.

Erlenmeyer-Kimling, L., Rock, D., Roberts, S.A., Janal, M., Kestenbaum, C., Cornblatt, B., Adamo, U.H., Gottesman, I.I., 2000. Attention, memory, and motor skills as childhood predictors of schizophrenia-related psychoses: the New York High-risk Project. American Journal of Psychiatry 157, 1416-1422.

Faraone, S.V., Seidman, L.J., Kremen, W.S., Pepple, J.R., Lyons, M.J., Tsuang, M.T., 1995. Neuropsychological functioning among the nonpsychotic relatives of schizophrenic patients: a diagnostic efficiency analysis. Journal of Abnormal Psychology 104, 286-304.

Feinberg, I., 1982. Schizophrenia: caused by a fault in programmed synaptic elimination during adolescence? Journal of Psychiatric Research 4, 319-334.

Feldman, M.J., Drasgow, J., 1981. The Visual-Verbal Test. Western Psychological Services, Los Angeles, CA. Original edition, 1959.

Fish, B., Shapiro, T., Halpern, F., Wile, R., 1965. The prediction of schizophrenia in infancy: III. A ten-year follow-up report of neurological and psychological development. American Journal of Psychiatry 121, 768-775.

Fletcher, J.M., Francis, D.J., Rourke, B.P., Shaywitz, S.E., Shaywitz, B.A., 1992. The validity of discrepancy-based definitions of reading disabilities. Journal of Learning Disabilities 25, 555-573.

Freund, R.J., Littell, R.C., Spector, P.C., 1986. SAS System for Linear Models. SAS Institute, Carey, NC.

Fucetola, R., Seidman, L.J., Kremen, W.S., Faraone, S.V., Goldstein, J.M., Tsuang, M.T., 2000. Age and neuropsychological function in schizophrenia: a decline in executive abilities beyond that observed in normal volunteers. Biological Psychiatry 48, 137-146.

Goldberg, T.E., Ragland, D., Torrey, E.F., Gold, J.M., Bigelow, L.B., Weinberger, D.R., 1990. Neuropsychological assessment of 
monozygotic twins discordant for schizophrenia. Archives of General Psychiatry 47, 1066-1072.

Goldberg, T.E., Torrey, E.F., Gold, J.M., Bigelow, L.B., Ragland, R.D., Taylor, E., Weinberger, D.R., 1995. Genetic risk of neuropsychological impairment in schizophrenia: a study of monozygotic twins discordant and concordant for the disorder. Schizophrenia Research 17, 77-84.

Golden, C., MacInnes, W., Ariel, R., Ruedrich, S., Chu, C.-C., Coffman, J., Graber, B., Bloch, S., 1982. Cross-validation of the ability of the Luria-Nebraska neuropsychological battery to differentiate chronic schizophrenics with and without ventricular enlargement. Journal of Consulting and Clinical Psychology 50, 87-95.

Goldstein, G., 1986. The neuropsychology of schizophrenia. In: Grant, I., Adams, K. (Eds.), Neuropsychological Assessment of Neuropsychiatric Disorders. Oxford University Press, New York, pp. $147-171$.

Grant, D.A., Berg, E.A., 1948. A behavioral analysis of degree of reinforcement and ease of shifting to new responses in a Weigltype card sorting problem. Journal of Experimental Psychology 38, 404-411.

Harvey, P.D., Silverman, J.M., Mohs, R.C., Parrella, M., White, L., Powchik, P., Davidson, M., Davis, K.L., 1999. Cognitive decline in late-life schizophrenia: a longitudinal study of geriatric chronically hospitalized patients. Biological Psychiatry 45, 32-40.

Heaton, R.K., 1981. Wisconsin Card Sorting Test Manual. Psychological Assessment Resources, Odessa, FL.

Heaton, R.K., Drexler, M., 1987. Clinical neuropsychological findings in schizophrenia and aging. In: Miller, N.E., Cohen, G.D. (Eds.), Schizophrenia and Aging: Schizophrenia, Paranoia, and Schizophreniform Disorders in Later Life. Guilford, New York, pp. $145-161$.

Heilman, K.M., Valenstein, E., 1979. Clinical Neuropsychology. Oxford University Press, New York.

Hooper, H.E., 1983. Hooper Visual Organization Test (VOT) Manual. Western Psychological Services, Los Angeles.

Jastak, S., Wilkinson, G.S., 1984. Wide Range Achievement TestRevised. Jastak Associates, Wilmington, DE.

Jones, P., Rodgers, B., Murray, R.M., 1994. Child developmental risk factors for adult schizophrenia in the British 1946 birth cohort. Lancet 344, 1398-1402.

Kimura, D., 1967. Functional asymmetry of the brain in dichotic listening. Cortex 3, 163-178.

Kremen, W.S., Buka, S.L., Seidman, L.J., Goldstein, J.M., Koren, D., Tsuang, M.T., 1998. IQ decline during childhood and adult psychotic symptoms in a community sample: a 19-year longitudinal study. American Journal of Psychiatry 155, 672-679.

Kremen, W.S., Seidman, L.J., Goldstein, J.M., Faraone, S.V., Tsuang, M.T., 1994. Systematized delusions and neuropsychological function in paranoid and nonparanoid schizophrenia. Schizophrenia Research 12, 223-236.

Kremen, W.S., Seidman, L.J., Faraone, S.V., Pepple, J.R., Lyons, M.J., Tsuang, M.T., 1995. The "3 Rs" and neuropsychological function in schizophrenia: a test of the matching fallacy in biological relatives. Psychiatry Research 56, 135-143.

Kremen, W.S., Seidman, L.J., Faraone, S.V., Pepple, J.R., Lyons, M.J., Tsuang, M.T., 1996. The "3 Rs" and neuropsychological function in schizophrenia: an empirical test of the matching fallacy. Neuropsychology 10, 22-31.

Kremen, W.S., Seidman, L.J., Faraone, S.V., Toomey, R., Tsuang, M.T., 2000. The paradox of normal neuropsychological function in schizophrenia. Journal of Abnormal Psychology 109, 743-752.
Kremen, W.S., Seidman, L.J., Faraone, S.V., Tsuang, M.T., 2001. Intelligence quotient and neuropsychological profiles in patients with schizophrenia and normal volunteers. Biological Psychiatry 50, 453-462.

Kremen, W.S., Lyons, M.J., Boake, C., Xian, H., Jacobson, K.C., Waterman, B., Eisen, S.A., Goldberg, J., Faraone, S.V., Tsuang, M.T., 2006. A discordant twin study of premorbid cognitive ability in schizophrenia. Journal of Clinical and Experimental Neuropsychology 28, 208-224.

Kurtz, M.M., 2005. Neurocognitive impairment across the lifespan in schizophrenia: an update. Schizophrenia Research 74, 15-26.

Luria, A.R., 1980. Higher Cortical Functions in Man. Oxford University Press, New York.

Palmer, B.W., Heaton, R.K., Paulsen, J.S., Kuck, J., Braff, D., Harris, M.J., Zisook, S., Jeste, D.V., 1997. Is it possible to be schizophrenic yet neuropsychologically normal? Neuropsychology 11, 437-446.

Reichenberg, A., Rabinowitz, J., Weiser, M., Mark, M., Kaplan, Z., Davidson, M., 2000. Premorbid functioning in a national population of male twins discordant for psychoses. American Journal of Psychiatry 157, 1514-1516.

Rey, A., 1941. L'Examen psychologique dans les cas d'encephalopathie traumatique. Les Archives de Psychologie 28, 286-340.

Russell, A.J., Munro, J.C., Jones, P.B., Hemsley, D.R., Murray, R.M., 1997. Schizophrenia and the myth of intellectual decline. American Journal of Psychiatry 154, 635-639.

Seidman, L.J., 1983. Schizophrenia and brain dysfunction: an integration of recent neurodiagnostic findings. Psychological Bulletin 94, 195-238.

Seidman, L.J., 1990. The neuropsychology of schizophrenia: a neurodevelopmental and case study approach. Journal of Neuropsychiatry and Clinical Neurosciences 2, 301-312.

Seidman, L.J., 1994. Listening, meaning, and empathy in neuropsychological disorders: case examples of assessment and treatment. In: Elliston, J.M., Weinstein, C.S. (Eds.), The Psychotherapist's Guide to Neuropsychiatry: Diagnostic and Treatment Issues. American Psychiatric Press, Washington, DC, pp. 1-22.

Seidman, L.J., Kremen, W.S., Koren, D., Faraone, S.V., Toomey, R., Tsuang, M.T., 2002. A comparative profile analysis of neuropsychological function in schizophrenia and bipolar psychoses. Schizophrenia Research 53, 31-44.

Seidman, L.J., Buka, S.L., Goldstein, J.M., Tsuang, M.T., 2006. Intellectual decline in schizophrenia: evidence from a prospective birth cohort 28 year follow-up study. Journal of Clinical and Experimental Neuropsychology 28, 225-242.

Silverstein, M.L., Zerwic, M.J., 1985. Clinical psychopathologic symptoms in neuropsychologically impaired and intact schizophrenics. Journal of Consulting and Clinical Psychology 53, 267-268.

Vincent, K.R., Castillo, I.M., Hauser, R.I., Zapata, J.A., Stuart, H.J., Cohn, C.K., O’Shanick, G.J., 1984. MMPI-168 Codebook. Ablex, Norwood, NJ

War Department, 1944. Army Individual Test Battery. Adjutant General's Office, Washington, DC.

Wechsler, D., 1945. A standardized memory scale for clinical use. Journal of Psychology 19, 87-95.

Wechsler, D., 1981. Manual for the Wechsler Adult Intelligence ScaleRevised. Psychological Corporation, San Antonio, TX.

Wechsler, D., 1987. Manual for the Wechsler Memory Scale-Revised. Psychological Corporation, San Antonio, TX.

Weickert, T.C., Goldberg, T.E., Gold, J.M., Bigelow, L.B., Egan, M.F., Weinberger, D.R., 2000. Cognitive impairments in patients with 
schizophrenia displaying preserved and compromised intellect. Archives of General Psychiatry 57, 907-913.

Weinberger, D.R., 1987. Implications of normal brain development for the pathogenesis of schizophrenia. Archives of General Psychiatry 44, 660-669.

Weintraub, S., Mesulam, M.-M., 1985. Mental state assessment of young and elderly adults in behavioral neurology. In: Mesulam,
M.-M. (Ed.), Principles of Behavioral Neurology. F.A. Davis, Philadelphia, PA, pp. 71-124.

Zammit, S., Allebeck, P., David, A.S., Dalman, C., Hemmingsson, T., Lundberg, I., Lewis, G., 2004. A longitudinal study of premorbid IQ Score and risk of developing schizophrenia, bipolar disorder, severe depression, and other nonaffective psychoses. Archives of General Psychiatry 61, 354-360. 